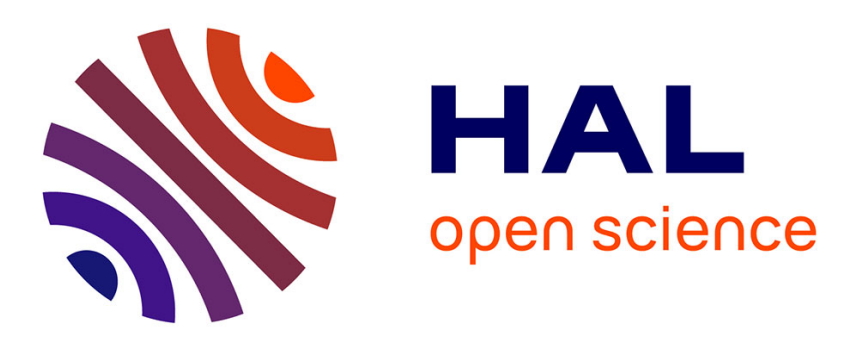

\title{
Study of Thermal Interfaces Aging for Power Electronics Applications
}

\author{
Jean-Pierre Ousten, Zoubir Khatir, Ludovic Menager
}

\section{To cite this version:}

Jean-Pierre Ousten, Zoubir Khatir, Ludovic Menager. Study of Thermal Interfaces Aging for Power Electronics Applications. Semiconductor Thermal Measurement and Management Symposium (SEMI-THERM), 2011 27th Annual IEEE, Mar 2011, San José, United States. pp.10-17, 10.1109/STHERM.2011.5767171 . hal-00628901

\section{HAL Id: hal-00628901 https://hal.science/hal-00628901}

Submitted on 4 Oct 2011

HAL is a multi-disciplinary open access archive for the deposit and dissemination of scientific research documents, whether they are published or not. The documents may come from teaching and research institutions in France or abroad, or from public or private research centers.
L'archive ouverte pluridisciplinaire HAL, est destinée au dépôt et à la diffusion de documents scientifiques de niveau recherche, publiés ou non, émanant des établissements d'enseignement et de recherche français ou étrangers, des laboratoires publics ou privés. 


\title{
Study of Thermal Interfaces Aging for Power Electronics Applications
}

\author{
J.-P. Ousten, Z. Khatir, L. Ménager \\ IFSTTAR, Institute of Science and Technology of Transport, Planning and Networks \\ Laboratory of New Technologies \\ 25 Allée des Marronniers, 78008 Versailles, France \\ jean-pierre.ousten@ifsttar.fr
}

\begin{abstract}
This paper presents new investigations on the aging of Thermal Interface Materials (TIM) subjected to thermal cycling conditions. The challenge was to design a specific and original set-up in order to not only undergo avionic temperature mission profile $\left(-50^{\circ} \mathrm{C} / 150^{\circ} \mathrm{C}\right)$ but also to perform standardized thermal characterization at always same conditions. Thermal conductivity is used as aging indicator. Several TIM materials (change phase, graphite and polymer based) have undergone more than 850 of such cycles. As a result, only the phase change material thermal interface has been affected with a 30\% decrease of initial thermal resistance.
\end{abstract}

\section{Keywords}

Thermal Interface Material, Thermal aging, Thermal conductivity, Static thermal characterization, Material interface degradation, Transient thermal analysis.

\section{Nomenclature}

$\lambda$ Global thermal conductivity from the thermal interface $\left(\mathrm{W} \cdot \mathrm{m}^{-1} \cdot \mathrm{K}^{-1}\right.$ )

Q Heat flow through the interface (W)

$\mathrm{P}_{\mathrm{ls}}$ Upper lateral losses from the experimental set-up (W)

e Thickness of the thermal interface under pressure (m)

S Thermal interface area $\left(\mathrm{m}^{2}\right)$

$\Delta \mathrm{T}$ Temperature discontinuity at the interface $\left({ }^{\circ} \mathrm{C}\right)$

\section{Introduction}

The current trend in power electronics is to design power modules with high power density and undergoing severe environmental constraints (thermal, mechanical, moisture ...). These considerations require modules with an efficient thermal management to ensure a good reliability. For this reason, the thermal resistance between the dies and the cooling system must be as low as possible. Especially, the heat transfer between device base-plate and heat sink should be maximized using appropriate Thermal Interface Materials (TIMs). Unfortunately, this thermal interface represents the largest part of the overall thermal resistance of the thermal circuit. Moreover, the modifications of the interface physical properties due to aging phenomena may be prejudicial for the heat transfer, and so induce temperature rises leading to the failure of the power module.

This paper presents a study on the aging of three kind of thermal interfaces used in power modules for aeronautics applications. The thermal aging applied to these interfaces is an environmental thermal cycling from $-50^{\circ} \mathrm{C}$ to $+150^{\circ} \mathrm{C}$. Up to date, few works have been reported concerning the thermal interfaces specifically dedicated to power electronics since they represent a very small part of the interfaces market $[1,2$, $3]$. Moreover, the aging of such thermal interfaces are almost not studied. Nevertheless, any structural alterations of these materials should result in changes in their thermal conductivity that we try to detect using appropriate characterizations during the aging process. The thermal conductivity is determined by a static thermal characterization based on the ASTM D5470 standard method [4]. This one allows performing a thermal characterization of the interfaces under pressure as in power modules. The thermal conductivity is measured along the aging process.

In the following sections, after a state of the art of thermal interfaces, we will present an original experimental set-up allowing both the aging and the characterizations of TIMs. Then, the thermal measurement methodology used to characterize the thermal interfaces will be described as well as the aging protocol. Experimental results on the evolution of the thermal conductivity of these interfaces during the aging are given and discussed. Finally, some conclusions and perspectives are presented.

\section{State of the Art of the thermal interfaces}

Most of thermal interfaces are composed of a polymer matrix such as silicone or epoxy resins, and thermally conductive pads such as boron nitride, aluminum, alumina, zinc oxide or silver. These interfaces have generally a thermal conductivity between $0.5 \mathrm{~W} \cdot \mathrm{m}^{-1} \cdot \mathrm{K}^{-1}$ and a dozen of W. $\mathrm{m}^{-1} \cdot \mathrm{K}^{-1}$, and thus always higher than that of air $\left(0.026 \mathrm{~W} \cdot \mathrm{m}^{-1} \cdot \mathrm{K}^{-1}\right)$. In power electronics applications, there are essentially five kinds of thermal interfaces which are used: thermal greases, elastomer films, thermal conductive adhesives, phase change materials and graphite sheets [5]. In this paper, only elastomer films, phase change materials and graphite sheets are considered.

\section{Experimental set-up}

From the literature, three methods are used to characterize TIMs thermal performances: laser flash method [6], calorimetric method [4] and thermal analysis through electronic assemblies $[7,8]$. As the objective is to investigate the aging effect on thermal characteristics under thermal cycling and pressure conditions, only the calorimetric method, based on the ASTM D5470 standard method [4], can meet the specifications.

An original experimental set-up which allows both thermal characterization and aging tests in an environmental chamber (thermal cycles between $-50^{\circ} \mathrm{C}$ and $150^{\circ} \mathrm{C}$ ) has been designed and realized (Fig.1). The challenge was that the TIM thermal characterizations must be performed at always same pressure conditions even after thermal cycling aging. Pressure 
levels are those usually encountered in power module interfaces (20 bars). As we will see in the following, the difficulty was to design a set-up which can absorb only in an elastic way thermal deformations due to temperature swings $\left(\Delta \mathrm{T}=200^{\circ} \mathrm{C}\right)$. Any inelastic deformations, such as plastic or visco-plastic, will inevitably lead to pressure decrease, which is undesired during thermal characterizations.

\begin{tabular}{|c|c|c|}
\hline $\begin{array}{l}\text { Material (Typical } \\
\text { compound) }\end{array}$ & Advantages & Drawbacks \\
\hline \multicolumn{3}{|c|}{ Thermal Greases (AlN, ZnO, Silicon Oil) } \\
\hline $\begin{array}{l}\text { Dispersed thermally } \\
\text { conductive ceramic } \\
\text { fillers in silicone or } \\
\text { hydrocarbon oils to } \\
\text { form a paste. }\end{array}$ & $\begin{array}{l}\text { - High bulk thermal } \\
\text { conductivity. } \\
\text { - Thin joint with } \\
\text { minimal attach } \\
\text { pressure involving low } \\
\text { thermal resistance. } \\
\text { - No cure required. } \\
\text { - No delamination. } \\
\text { - Low cost. }\end{array}$ & $\begin{array}{l}\text { Pump-out, phase } \\
\text { separation or } \\
\text { migration. } \\
\text { - Dry-out over time } \\
\text { reducing reliability. } \\
\text { - Thickness difficult to } \\
\text { control. } \\
\text { - Excess grease can } \\
\text { flow out beyond the } \\
\text { edges, likely source } \\
\text { of pollution. }\end{array}$ \\
\hline \multicolumn{3}{|c|}{ Gels (Al, Ag, Silicon, Olefin) } \\
\hline $\begin{array}{l}\text { Compounds are } \\
\text { converted to a cured } \\
\text { rubber film after } \\
\text { application at the } \\
\text { thermal interface. } \\
\text { Initially flow as } \\
\text { freely as grease. }\end{array}$ & $\begin{array}{l}\text { - Good bulk thermal } \\
\text { conductivity. } \\
\text { No pump out or } \\
\text { migration. }\end{array}$ & $\begin{array}{l}\text { Processing/Cure } \\
\text { needed. } \\
\text { - Moisture issues. }\end{array}$ \\
\hline \multicolumn{3}{|c|}{ Elastomers (BN, Alumina, Silicone, Urethane Rubbers) } \\
\hline $\begin{array}{l}\text { Silicone elastomer } \\
\text { paste filled with } \\
\text { thermally conductive } \\
\text { ceramic particles } \\
\text { reinforced with } \\
\text { woven glass fiber or } \\
\text { dielectric film. }\end{array}$ & $\begin{array}{l}\text { - Conforms to surface } \\
\text { irregularities. } \\
\text { - No pump out. }\end{array}$ & $\begin{array}{l}\text { - Processing/Cure } \\
\text { needed. } \\
\text { - Stress at the } \\
\text { interface. } \\
\text { - Resin-Filler } \\
\text { separation. }\end{array}$ \\
\hline \multicolumn{3}{|c|}{ Adhesive Tapes (Ag filled epoxies) } \\
\hline $\begin{array}{l}\text { Double sided } \\
\text { pressure sensitive } \\
\text { adhesive films filled } \\
\text { with ceramic powder } \\
\text { and supported with } \\
\text { either aluminum foil } \\
\text { or polyimide film. }\end{array}$ & $\begin{array}{l}\text { - High bulk thermal } \\
\text { conductivity. } \\
\text { - No pump out. } \\
\text { - Gap filling. } \\
\text { - Film form format. }\end{array}$ & $\begin{array}{l}\text { - Very high contact } \\
\text { resistance. } \\
\text { - Need high clamping } \\
\text { pressure. }\end{array}$ \\
\hline \multicolumn{3}{|c|}{$\begin{array}{l}\text { Phase Change (Polyolefins, Epoxies, Polyesters, Acrylics, BN, } \\
\text { Alumina) }\end{array}$} \\
\hline $\begin{array}{l}\text { Thixotropic, paste } \\
\text { like product which } \\
\text { when heated } \\
\text { (crossover } \\
\text { temperature) turns to } \\
\text { liquid, fills voids and } \\
\text { returns to a solid. }\end{array}$ & $\begin{array}{l}\text { - Conforms to surface } \\
\text { irregularities. } \\
\text { - No cure needed. } \\
\text { - Film form format. }\end{array}$ & $\begin{array}{lr}\bullet \text { Utilized with } & \text { carriers, } \\
\text { increasing } & \text { thermal } \\
\text { resistivity. } & \\
\text { - Lower } & \text { thermal } \\
\text { conductivity } & \text { than } \\
\text { grease. } & \\
\text { - Technology } & \\
\text { limitations. } & \end{array}$ \\
\hline \multicolumn{3}{|c|}{ Graphite sheets (Graphite) } \\
\hline $\begin{array}{l}\text { Graphite flakes } \\
\text { processed into sheet } \\
\text { by the combination } \\
\text { of a chemical, } \\
\text { thermal and } \\
\text { mechanical and } \\
\text { treatment }\end{array}$ & $\begin{array}{l}\text { - Good bulk thermal } \\
\text { conductivity. } \\
\text { - No pump out. } \\
\text { - No cure needed. } \\
\text { - Sheet form format. }\end{array}$ & $\begin{array}{llr}\bullet \text { Much lower thermal } \\
\text { conductivity in the } \\
\text { thickness due to } \\
\text { anisotropic } & \text { crystal } \\
\text { structure. } & \\
\text { - Delamination. } & \end{array}$ \\
\hline
\end{tabular}

Table I: Thermal interface materials.
The system consists of two aluminum blocks between which is inserted the thermal interface, a heat source in its upper part and a cooler in the lower part. The objective is to obtain, during thermal characterizations, a homogeneous heat flow and perfectly controlled along the two aluminum blocks from the heat source to the heat sink. The measurement accuracy depends on the ability to minimize heat losses and to precisely control the heat flow. To avoid heat losses from top and lateral sides, a thermal insulation is provided by a double layer of Teflon polymer plates (PTFE) of $6 \mathrm{~mm}$ thick each. In addition, a compensating heat source is placed above the main heat source to offset any possible heat losses up. The heat source is performed by four cartridge heaters $(Q 6.5 \mathrm{~mm})$ that can dissipate up to $1 \mathrm{~kW}$ and which are located inside a $20 \mathrm{~mm}$ thick copper plate in order to spread the heat flow. This one can reach $15 \mathrm{~W} / \mathrm{cm}^{2}$. Because of its role, the electrical power of the compensating heat source is lower than the main source, using only three cartridge heaters. The two heat sources are regulated by comparison with a same temperature set value. This allows a fast control and avoids excessive temperature rise of heating elements that can lead to degradations.

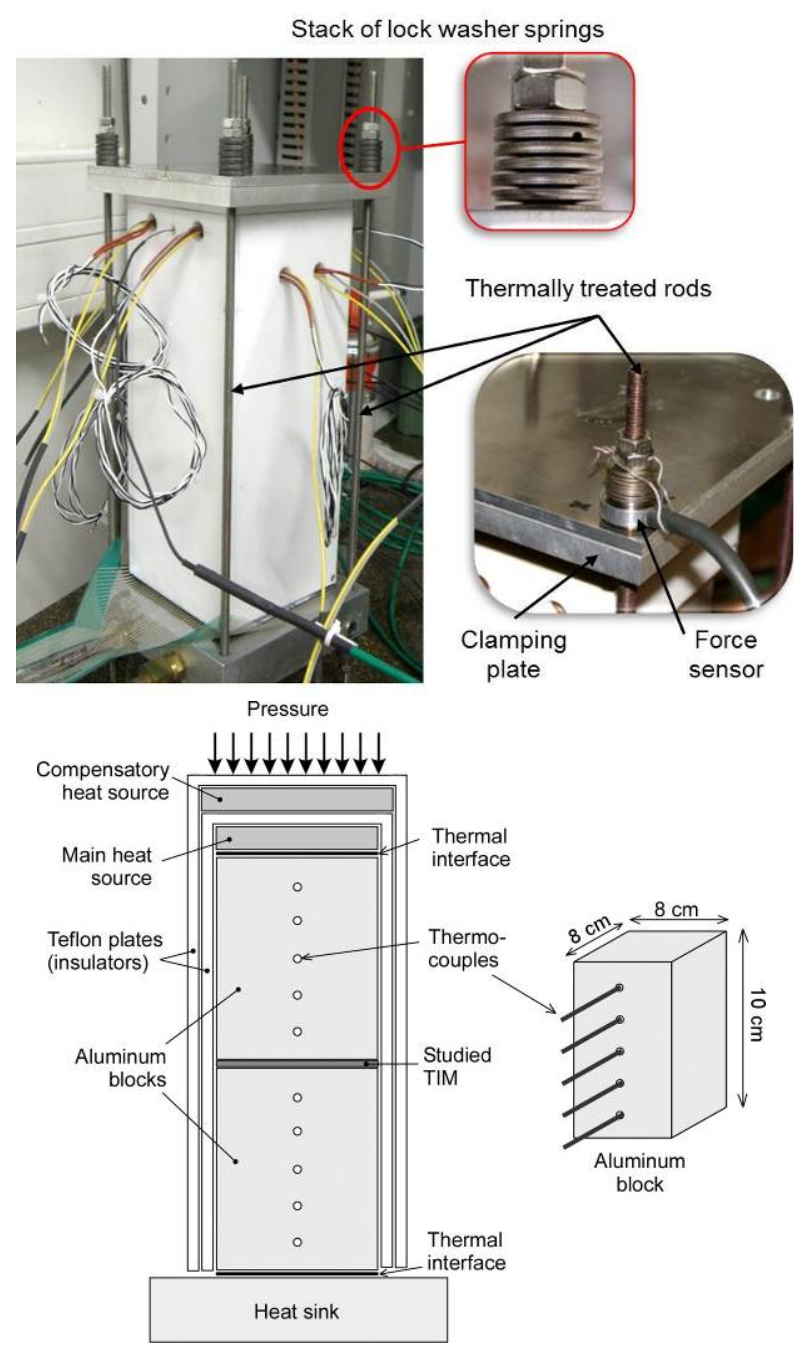

Figure 1: Experimental set-up. 
The assembly is kept under pressure by clamping as shown in figure 1 . The pressure level is set at that usually obtained in the thermal interface between electronic power modules and heat sinks. As already said, the difficulty was to design a set-up which can absorb only in an elastic way thermal deformations due to temperature swings. This has been done by using treated rods and well calibrated stacks of lock washer springs for clamping. Stacks of springs have an elastic behavior during thermal cycling and used rods can undergo temperature swings, from $-50^{\circ} \mathrm{C}$ to $150^{\circ} \mathrm{C}$, without alteration of their mechanical properties. These rods have a larger stiffness than the spring stacks as well as a very high yield stress. By this way, all thermal deformations due to temperature variation during thermal cycling are totally absorbed by the spring stacks. No part of the assembly is subjected to inelastic deformation. So, regular thermal characterizations of TIM, during the aging, are always performed under the same pressure conditions. In order to control the pressure values during the thermal characterizations, a force sensor (Fig.1) has been used in one of the rods.

As preliminary measurements, the pressure distribution has been measured at the lower interface of the assembly, between the bottom aluminum block and the heat sink by using a sheet of matrix pressure sensor which can be seen in figure 1. This is done before any thermal measurements and aging. An example of such distribution is given in figure 2 where a mean pressure value is around 20 bars. Then, this sensor sheet is removed in order to proceed to the aging and thermal characterizations.

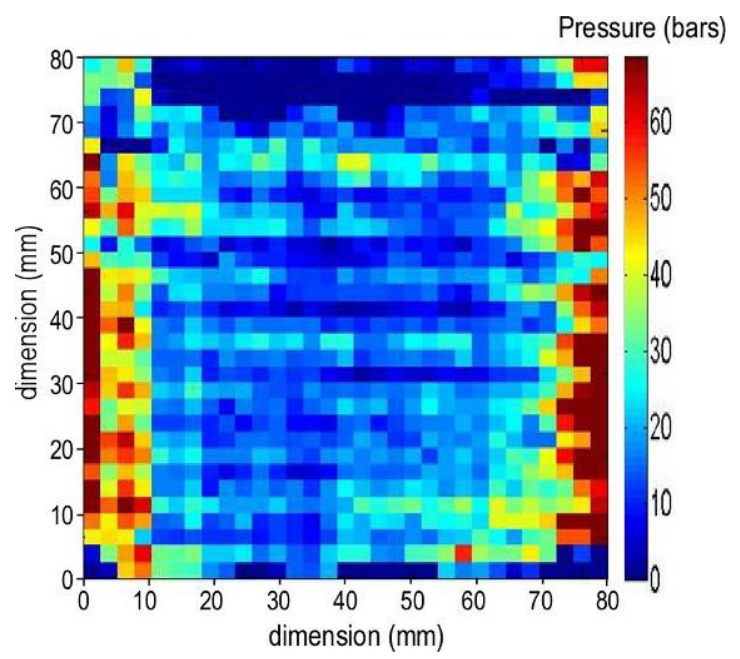

Figure 2: Pressure distribution.

Each aluminum block is equipped with five $\mathrm{T}$ type thermocouples in the center line, regularly spaced vertically. Two type $\mathrm{K}$ thermocouples are used to regulate the temperature of both heat sources. Finally, inlet and outlet water temperatures from the water box are measured using PT100. They allow to measure the exchange temperature of the cold source and to control heat losses from system by comparing the amount of heat injected by the source and removed by the coolant.

\section{Aging protocol and thermal characterization method}

\subsection{Aging protocol}

Three experimental set-ups have been realized in order to test three different TIMs. These materials have been chosen for avionic applications and are given in table II.

\begin{tabular}{|c|c|c|c|}
\hline TIM & $\begin{array}{c}\text { Compelma } \\
\text { T014 } \\
{[\text { CO-GhJ050] }}\end{array}$ & $\begin{array}{c}\text { Egraf 1205A } \\
{[\text { HT-1205A] }}\end{array}$ & $\begin{array}{c}\text { Hi-Flow 300P } \\
{[\text { [HF300P-0.127] }}\end{array}$ \\
\hline Material & Elastomer film & Graphite sheet & Phase change \\
\hline Compound & Polymer & Graphite & Polyimide \\
\hline $\begin{array}{c}\text { Ther. conduct. } \\
\left(\mathrm{W} . \mathrm{m}^{-1} \cdot \mathrm{K}^{-1}\right)\end{array}$ & 14 & 10 & 1.6 \\
\hline
\end{tabular}

Table II: Material data from data-sheets.

Figure 3 shows the schematic aging protocol used for this study. After the three assemblies are at the correct pressure level, preliminary thermal characterizations are done in order to have initial measured values of thermal resistances before thermal cycling. This characterization is detailed in the next section. At this step, the TIMs thicknesses are measured by an optical mean. Then, the assemblies are arranged in an environmental chamber in order to undergo thermal cycles between $-50^{\circ} \mathrm{C}$ to $+150^{\circ} \mathrm{C}$ (Fig.4). Measured temperature cycle profile for each assembly is given in figure 5 .

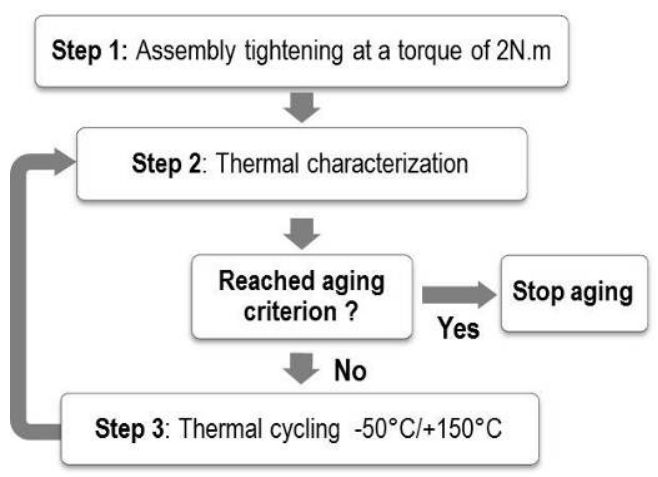

Figure 3: Schematic aging protocol.

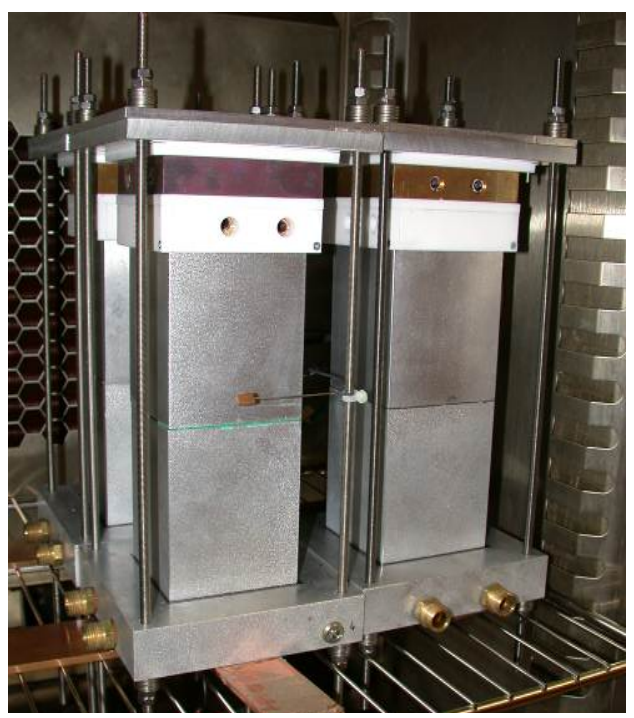

Figure 4: Experimental devices in the climatic chamber. 


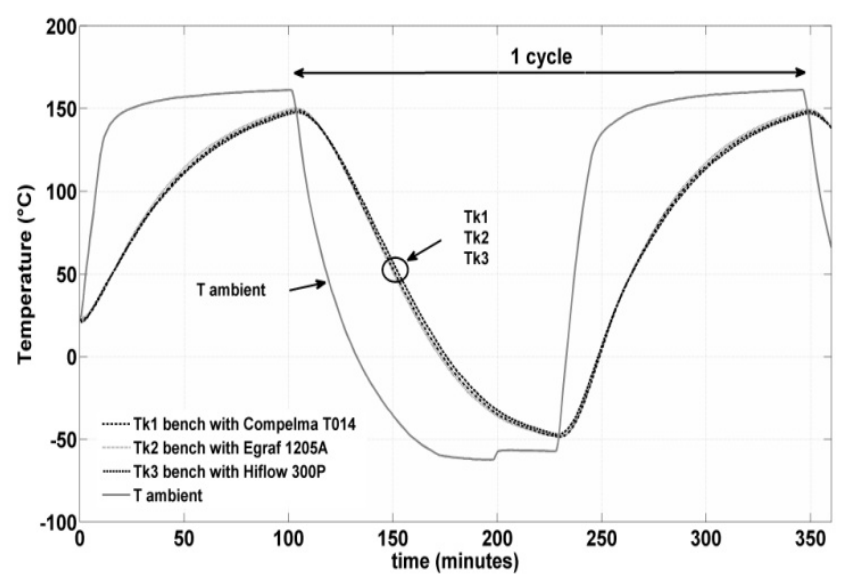

Figure 5: Temperature profile on a cycle.

It can be seen that same thermal cycling conditions are applied to all benches as shown by the measured temperatures (Tk1, Tk2, Tk3). In addition, the pressure level in one of the assembly has been monitored during the thermal cycling and controlled during thermal characterizations. This is done by the force sensor (Fig.1).

As shown in figure 3, thermal characterizations of TIMs are regularly done during aging until an aging criterion is reached. This criterion is based on a significant thermal resistance variation of the interface.

\subsection{Thermal characterization method}

The characterization method is based on the ASTM D5470 standard method [4]. It is established on an ideal heat flow propagation between two parallel surfaces where is inserted the studied interface with uniform thickness. One surface is in contact with a cold source in order to remove the heat flow through the interface. The other one is in contact with a heat source to produce a uniform thermal gradient in a normal direction to surfaces. If we assume that the lateral faces of the system are adiabatic, the entire heat flow goes uniformly through the interface. In practice, there are heat losses which must be evaluated. The temperature discontinuity $\Delta \mathrm{T}$ at the interface is due to the total thermal resistance of the interface. This one is composed of the interface thermal resistance and the contact resistances:

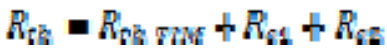

Some interfaces, available with different thicknesses, allow to deduce the sum $\left(R_{\mathrm{F} I}+R_{\mathrm{gE}}\right)$. Unfortunately, the three TIMs used for this study are not available in different thickness values and we are unable to extract their contact resistance values. So, the only measured parameter we carry out our investigations is the overall thermal resistance Rth. Similarly, although most objectionable, we use an overall or effective thermal conductivity of the interface that takes account of the contacts:

$$
a_{e t t}=\frac{\left(Q-P_{u n}\right)=\epsilon}{\Delta T \cdot S}
$$

where e is the thickness of the thermal interface (under pressure), $\mathrm{S}$ the interface area, $\mathrm{Q}$ the heat flow through the interface and $\mathrm{P}_{\text {ull }}$ the lateral losses of the upper aluminum block from the experimental set-up (Fig.6).

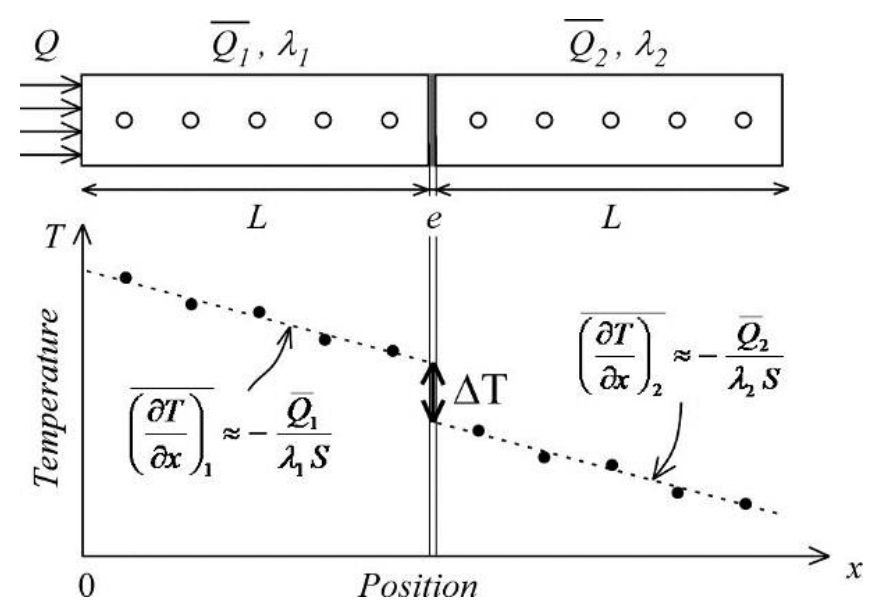

Figure 6: Thermal characterization principle.

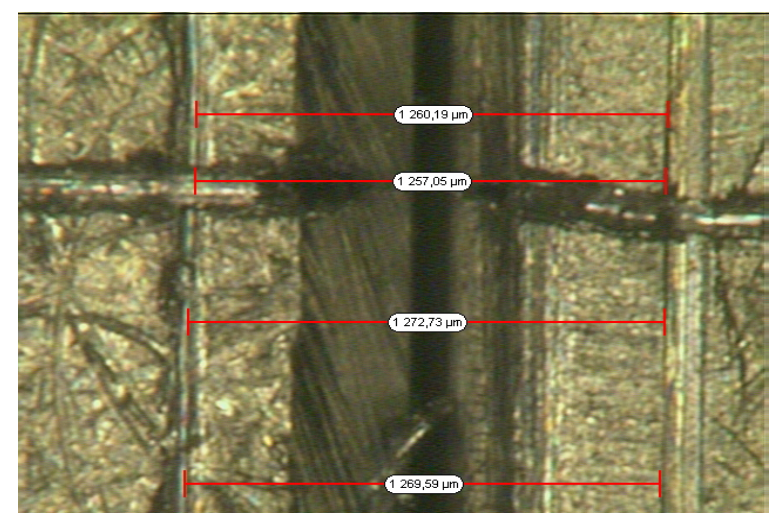

a) Without the thermal interface (initially).

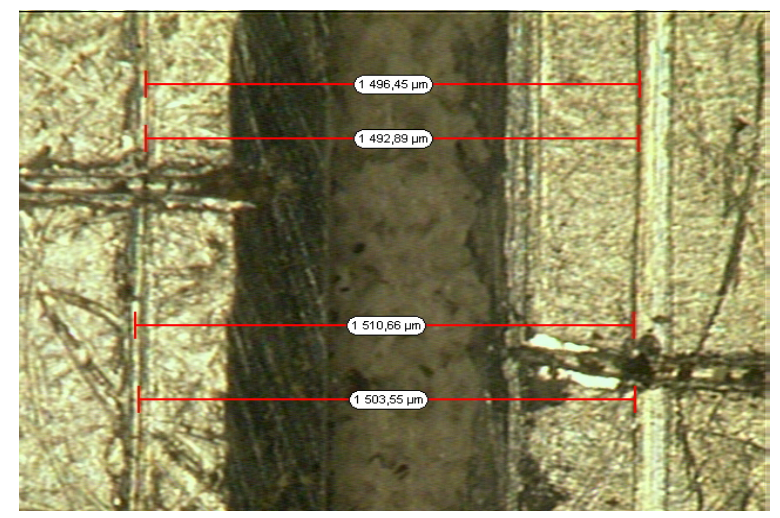

b) With the TIM (Compelma T014), during aging.

Figure 7: Thickness measurement.

The evaluation of the heat flow through the interface requires the knowledge of the heat losses between the heat source and the interface. The measurement of the thermal conductivity requires the interfaces thickness measurement. This one is achieved at room temperature by optical means (Fig.7). Thickness measurement is averaged over six points, two points per side on three of the four sides. This measurement is performed between two markers located opposite to each aluminum block on both sides of the interface. It's actually a difference of 2 measurements, one being made before the insertion of the interface (Fig.7a) and 
the other after insertion and when the assembly was under pressure (Fig.7b). Figure 8 gives the measured thicknesses throughout the aging and show that it remains fairly stable.

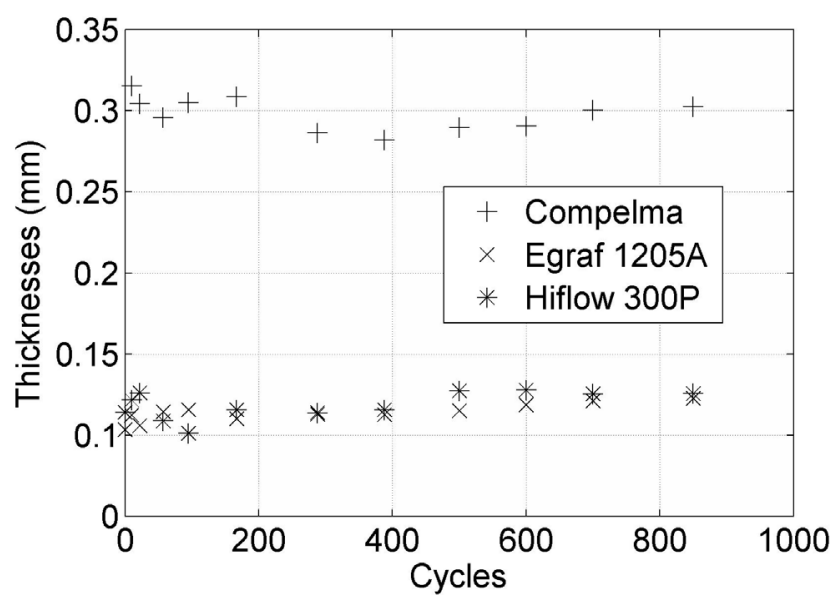

Figure 8: TIMs thickness versus cycles number.

As mentioned previously, the interface being subjected to pressure, this one will be always the same for all characterizations. Indeed, a pressure variation can impact the TIM thickness, contact resistances, temperature distribution, and so the interface thermal conductivity.

\section{Experimental results}

The interface materials have undergone up to 850 thermal cycles between $-50^{\circ} \mathrm{C}$ and $150^{\circ} \mathrm{C}$ like shown in figure 5 . Thermal characterizations were performed regularly during this aging at the same pressure level, around 22 bars. In order to detect any changes in the thermal resistance and thermal conductivity interfaces, very close thermal characterizations were performed during the first hundred cycles of aging, then less frequently thereafter. Measurements are shown below with the estimated error bars. For obvious reasons of confidentiality, the following results are given in normalized units.

The Compelma interface (elastomer film) exhibits no significant changes in either thermal resistance or thermal conductivity (Fig.9). The light visible variations are in the order of the error bars. So we can assume that no aging process has affected this TIM at 850 cycles.

Concerning the Egraph interface (graphite), we can observe that no aging effect takes place (Fig.10). In the contrary, this TIM seems to improve its thermal performances lightly, even if error bars are important.

At least, concerning the Hiflow interface (change phase material), we can observe that the overall thermal resistance (interface and contacts) have increased up to $30 \%$ (Fig.11). This behavior is probably due to a deterioration of the material structure linked to its aging. It should be observed that there is no significant variation in the thermal resistance value from the seven hundredth cycle.
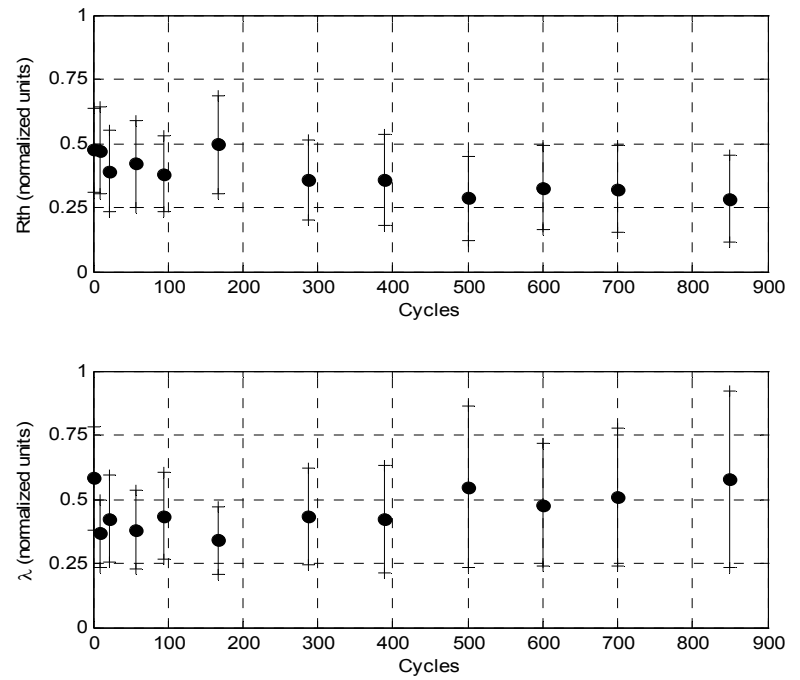

Figure 9: Evolution of the Compelma T014 thermal resistance and conductivity versus cycles number.
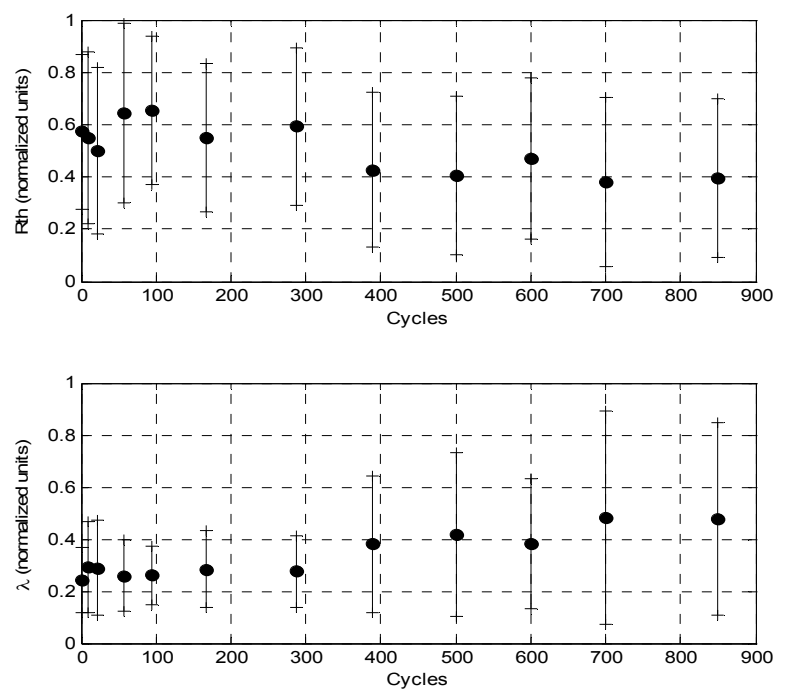

Figure 10: Evolution of the Egraf 1205A thermal resistance and conductivity versus cycles number.
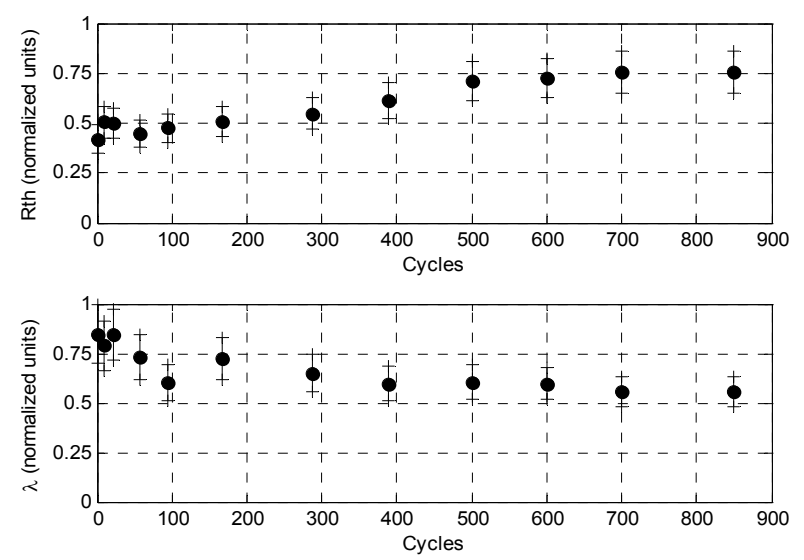

Figure 11: Evolution of the Hiflow 300P thermal resistance and conductivity versus cycles number. 
So as to understand the changes that are likely to occur during aging on TIMs, it is necessary to acquire all relevant informations on their constituents and their structure in the initial state in order to be compared with the final state. Indeed, it is likely that during the aging of TIMs appear a chemical and/or physical process. Therefore, we use material analysis best suited techniques to determine the chemical composition and topography of the tested TIMs. These same analysis techniques will be employed at the end of the cycling when aging will be achieved. These analyses should enable us to understand the physicochemical processes that occur during aging and lead to degradation of structures and material characteristics.

Next pictures present the SEM images of the tested TIMs before their mounting on the experimental set-up. Figure 12 shows the structure of the Compelma material whereas figure 13 gives the graphite structure of the Egraph one. For the first material, EDX analyses have shown presence of aluminum, oxygen and silicon.

In figure 14, we can see SEM images of the phase change material before (a) and after (b) the first phase change. In these last photos, EDX analyses have detected mainly aluminum, carbon, oxygen and some traces of silicon.

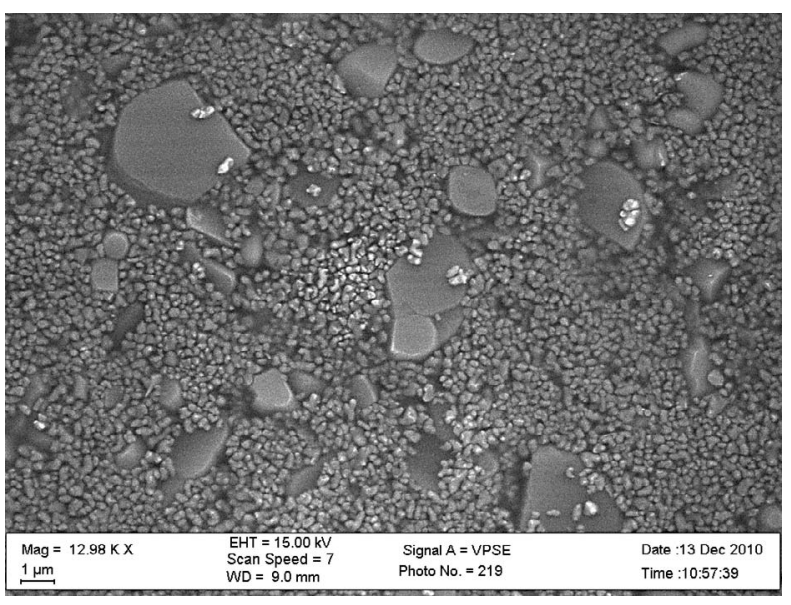

Figure 12: Compelma T014 SEM image before step 1.

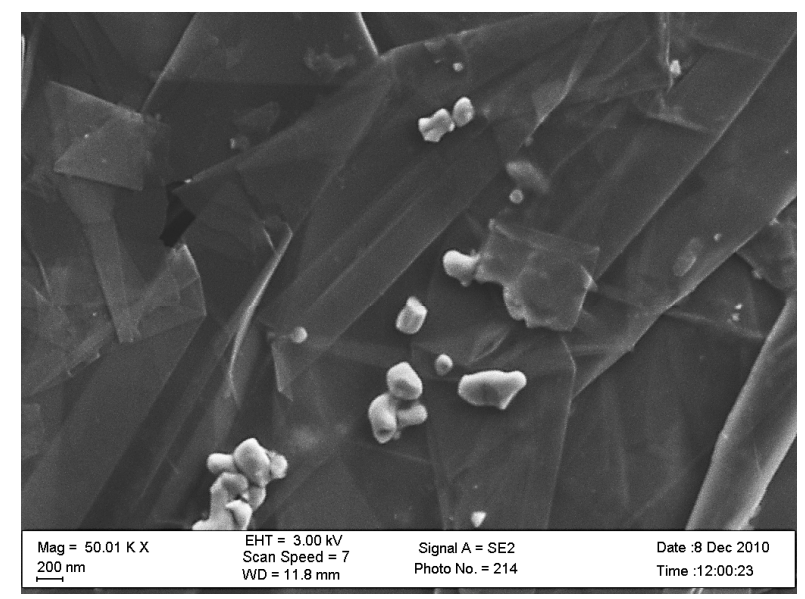

Figure 13: Egraf 1205A SEM image before step 1.

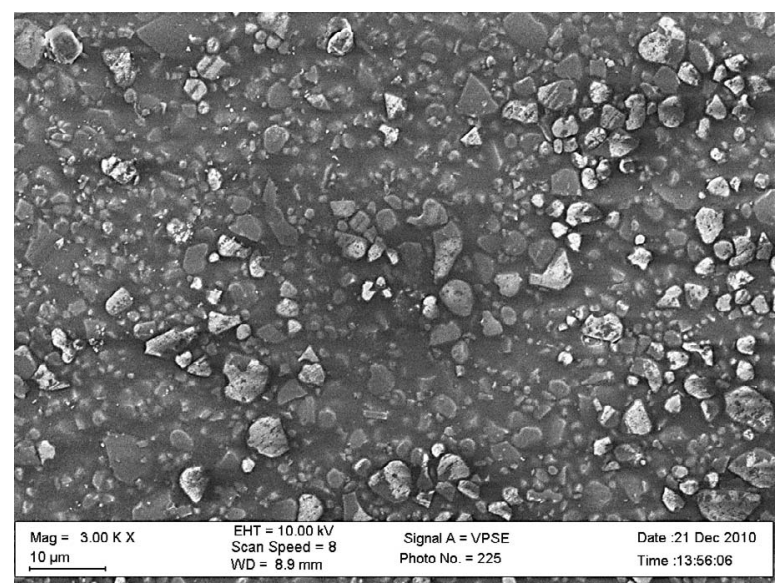

a) before phase change.

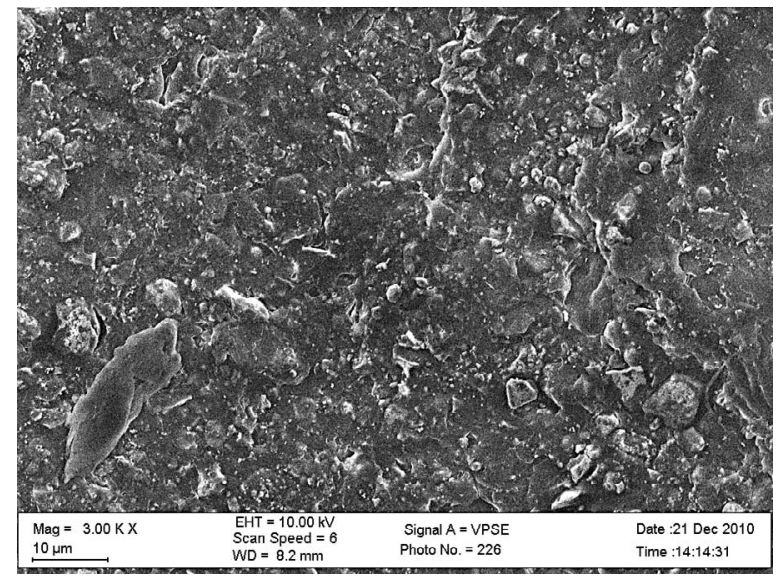

b) after phase change.

Figure 14: Hiflow 300P SEM image before step 1.

\section{Conclusion and perspectives}

This paper has presented a study on the aging of several TIM materials (change phase, graphite and polymer based) by passive thermal cycling. The thermal conductivity has been the chosen parameter to follow the aging of the interfaces. It has been achieved by a static thermal characterization based on the ASTM D5470 standard method. Furthermore it discusses the aging of thermal interfaces dedicated to high power electronics, its interest lies also in the presentation of a specific and original experimental set-up allowing both thermally characterizing and aging in an environmental chamber of TIMs under pressure. To date, 850 cycles avionic temperature mission profile $\left(-50^{\circ} \mathrm{C} / 150^{\circ} \mathrm{C}\right)$ have been made. As a result, only the phase change material thermal interface has been affected with a 30\% decrease of initial thermal resistance.

These aging experiments will be continued until 1500 cycles. Then, full structural material analyses will be done on the aged TIMs. Further investigations are planned, in adapted devices, in order to complete the conducted experimental analyses. In particular, additional transient thermal characterizations are under development in order to detect eventually some effects due to dynamic material properties such as thermal capacitance. 


\section{Acknowledgments}

Authors would like to thank their colleague Dr. Kociniewski for the SEM and EDX analyses. This study has been realized in the framework of the French project program Thermelec and supported by the regional council of Ile-de France.

\section{References}

1. B.C. Ray, "Temperature effect during humid ageing on interfaces of glass and carbon fibers reinforced epoxy composites", Journal of Colloid and Interface Science 298, pp. 111-117, 2006.

2. M. Schulz, "Evaluating TIM below power electronics modules separating measurement from fortune-telling", ECPE Workshop, Nuremberg, Germany, May 2010.

3. U. Scheuermann, "Experience with TIMs in qualification and field applications", ECPE Workshop, Nuremberg, Germany, May 2010.

4. American Society for Testing and Materials, "Standard test methods for thermal transmission properties of thin thermally conductive solid electrical insulation materials", ASTM Standard D5470-06, 2006.

5. S. Narumanchi, M. Mihalic and K. Kelly, "Thermal interface materials for power electronics applications", IEEE Intersociety Conference on Thermal and Thermomechanical Phenomena in Electronic Systems, Orlando, United States, July 2008.

6. American Society for Testing and Materials, "Standard test method for thermal diffusivity by the flash", ASTM Standard E1461-01, 2001.

7. R. Schacht, D. May, B. Wunderle and al., "Characterization of thermal interface materials to support thermal simulation", IEEE International Workshop on Thermal Investigation of ICs and Systems, Nice Côte d'Azur, France, September 2006.

8. B. Smith, T. Brunschwiler and B. Michel, "Utility of transient testing to characterize thermal interface materials", IEEE International Workshop on Thermal Investigation of ICs and Systems, Budapest, Hungary, September 2007. 